\title{
Sistem Informasi Penyewaan Kos dengan Fitur Google Maps
} API

\author{
Boarding House Website Information System Featuring Google Maps \\ API
}

\author{
Danendra Khansa Pallas Wahyudi*1, Soetam Rizky Wicaksono ${ }^{2}$ \\ 1,2 Universitas Ma Chung Malang \\ e-mail: 321710002@student.machung.ac.id ${ }^{1}$, soetam.rizky@machung.ac.id ${ }^{2}$
}

\begin{abstract}
Abstrak
OKOS adalah sistem informasi penyewaan kos secara online yang dapat memudahkan para pencari kos memilih kos yang diinginkan, selain itu pemilik kos juga dapat mendaftarkan tempat usaha kamar kos yang dimilikinya. OKOS dibuat untuk memenuhi kebutuhan para pencari kos dari luar kota agar lebih terbantu dalam mencari tempat kos dan juga para pemilik kos yang dapat terbantu dalam mempromosikan usaha kos miliknya. Metode yang digunakan untuk melakukan penelitian pembuatan OKOS adalah SDLC waterfall yang terdiri dari planning, analysis, design, implementation, testing, dan maintenance. Kesimpulan dari dilakukannya pembuatan website sistem informasi OKOS adalah OKOS dapat memenuhi kebutuhan pemilik kos dan pencari kos karena OKOS dapat menjadi perantara antara pencari kos dengan pemilik kos walau ada di kota yang berbeda. Selain itu OKOS menyediakan informasi yang cukup lengkap sehingga pencari kos dapat memilih kos berdasarkan jenis kos, fasilitas, harga, luas kamar, penghuni maksimal per kamar, hingga peta lokasi kos. Saran yang dapat penulis sampaikan adalah perlu adanya penelitian lebih lanjut tentang hal apa saja yang menjadi pertimbangan bagi para pencari kos untuk memilih kos yang diinginkan atau yang dibutuhkan agar dapat menjadi pertimbangan para pemilik kos atau pengembang aplikasi yang mirip dengan OKOS untuk menarik perhatian para pencari kos.
\end{abstract}

Kata Kunci: SDLC, sistem informasi, tempat kos, website

\begin{abstract}
OKOS is an online boarding information system that can make it easier for boarding house seekers to choose the boarding house they want, besides that boarding house owners can also register their boarding house business premises. OKOS was created to meet the needs of boarding house seekers from outside the city to be more helpful in finding a boarding house and boarding house owners who can be helped in promoting their boarding house business. The method used to research the creation of the OKOS is the SDLC waterfall which consists of planning, analysis, design, implementation, testing, and maintenance. The conclusion from making the OKOS information system website is that OKOS can meet the needs of boarding house owners and boarding house seekers because OKOS can be an intermediary between boarding house seekers and boarding house owners even though they are in different cities. In addition, OKOS provides complete information so that boarding house seekers can choose a boarding house based on the type of boarding house, facilities, price, room area, maximum occupants per room, to a map of the boarding location. The suggestion that the author can convey is that there is a need for further research on what things are considered for boarding house seekers to choose the desired or needed boarding house so that it can be considered by boarding house owners or application developers like OKOS to attract the attention of boarding house seekers.
\end{abstract}

Keywords: boarding house, information system, SDLC, website

\section{Pendahuluan}

Berdasarkan berita dari Merdeka.com, kota Malang memiliki julukan kota Pendidikan bahkan sejak masa Hindia Belanda karena pada kisaran tahun 1914-1939 pertumbuhan jumlah sekolah di kota Malang sangat pesat [1]. Selain itu berdasarkan berita dari Surya Malang, rata-rata pertumbuhan jumlah mahasiswa di kota Malang meningkat sekitar 5-10 persen setiap tahun, dan peningkatan tersebut sebagian besar disebabkan oleh mahasiswa dari luar kota Malang [2]. Karena meningkatnya pelajar dari luar kota Malang 
maka bisnis kos adalah salah satu bisnis yang paling merasakan dampak dari meningkatnya pelajar dari luar kota.

Beberapa sistem informasi penyewaan kos yang sudah tersedia saat ini dan serupa dengan OKOS adalah Mamikos dan Cari-Kos.com, kedua sistem informasi tersebut juga menyediakan fitur peta lokasi kos. Jika dilihat pada halaman website dari kedua sistem informasi tersebut, peta yang ditampilkan pada halaman Mamikos adalah peta dari OpenStreetMap dan peta yang ditampilkan pada halaman Cari-Kos.com adalah peta dari Here, sedangkan peta yang digunakan pada OKOS adalah Google Maps. Berdasarkan berita dari Suara.com, Google Maps masih menjadi peta digital yang paling banyak digunakan di seluruh dunia [3]. Berdasarkan artikel dari Suzuki, Google Maps telah diunduh lebih dari 4 miliar di Playstore, selain itu Google Maps juga dapat digunakan untuk melihat tempat-tempat seperti restoran, pom bensin, dan rumah ibadah [4]. Berdasarkan berita dan artikel yang telah disebutkan sebelumnya maka dipilihnya Google Maps karena masyarakat lebih familier dengan Google Maps, selain itu di dalam Google Maps juga terdapat informasi lebih lengkap tentang tempat-tempat seperti restoran, pom bensin, dan rumah ibadah.

OKOS adalah sistem informasi penyewaan kos secara online yang dapat memudahkan para pencari kos memilih kos yang diinginkan, selain itu pemilik kos juga dapat mendaftarkan tempat usaha kamar kos yang dimilikinya. Dalam website OKOS terdiri dari empat tipe pengguna yaitu pencari yang nanti menjadi penyewa, pemilik, dan admin (perantara). Pencari kos dapat mencari, mendaftarkan diri, dan memesan kamar kos. Penyewa kos dapat melakukan transaksi dengan pemilik kos, memperpanjang sewa kamar kos, memberikan rating ke pemilik kos, dan mendapat tagihan pembayaran sewa. Pemilik kos dapat mendaftarkan kos, mengubah data kos, memberikan diskon, menagih penyewa kos, menerima pembayaran booking dari admin, menerima perpanjangan sewa, memberi rating ke penyewa, dan menerima laporan keuangan. Admin dapat mengkonfirmasi pendaftaran akun pemilik kos, memvalidasi bukti transfer dari penyewa kos, memblokir penyewa maupun pemilik, mendapatkan fee dari hasil booking, dan mengirimkan tagihan ke penyewa.

API (Application Programming Interface) Google Maps adalah alat yang digunakan untuk menampilkan lokasi atau peta dari suatu tempat dengan mengakses server Google Maps [5]. Sedangkan menurut sumber lain, Google Maps API adalah teknologi yang dikembangkan Google dan digunakan untuk menanamkan Google Maps pada suatu aplikasi yang tidak dibuat oleh Google [6]. Dari kedua pengertian tentang API Google Maps yang telah disebutkan maka dapat disimpulkan bahwa API Google Maps merupakan alat yang digunakan oleh pengembang suatu aplikasi untuk menampilkan peta dari Google Maps pada aplikasi yang dibuat [7], [8].

Penelitian terdahulu tentang website kos dari Pradini menyimpulkan bahwa sistem informasi tersebut dapat memudahkan pemilik kos dalam menyediakan informasi tentang kamar kos dan dengan fasilitas yang ada. Selain itu sistem informasi pemesanan rumah kost tersebut dapat menghemat waktu dan tenaga karena membantu pengguna dalam memesan rumah kos secara online [9]. Penelitian terdahulu lainnya yang membahas tentang website kos dari Sagita dan Simpony mengatakan bahwa sistem informasi tersebut dapat menjadi media untuk menyebarkan iklan kos yang aman dan cepat, selain itu juga sebagai wadah bagi para pebisnis kos dalam memasarkan kosnya [10]. Dari kedua penelitian terdahulu yang telah dibahas, terdapat perbedaan dalam segi fitur. Perbedaan OKOS dengan kedua penelitian yang telah disebutkan sebelumnya adalah OKOS memiliki beberapa fitur tambahan seperti rating, perpanjangan sewa, diskon, laporan keuangan, dan melaporkan pengguna.

Sehingga berdasarkan keterangan yang sudah dijabarkan maka diperlukan pembuatan sistem informasi dengan fitur yang dapat mempermudah para pencari kos dari luar kota agar lebih terbantu dalam mencari tempat kos dan juga para pemilik kos yang dapat terbantu dalam mempromosikan usaha kos miliknya.

\section{Metode Penelitian}

Metode yang digunakan untuk melakukan penelitian pembuatan website OKOS adalah SDLC waterfall. System Development Life Cycle (SDLC) merupakan metode yang digunakan dalam pengembangan sistem dan identik dengan teknik pengembangan waterfall karena memiliki tahapan yang menurun dari atas ke bawah [11]. Sedangkan menurut sumber lain, SDLC merupakan siklus dalam pengembangan atau pembuatan sistem informasi yang memiliki tujuan untuk menyelesaikan suatu masalah dengan efektif yang terdiri dari beberapa tahapan yaitu planning, analysis, design, implementation, testing, dan maintenance [12]. Dipilihnya metode waterfall karena pada metode waterfall setiap tahap harus diselesaikan dengan baik sebelum melanjutkan ke tahap selanjutnya sehingga pembuatan sistem menjadi lebih terorganisir.

JINITA Vol. 3, No. 2, December 2021 


\section{Planning}

Penelitian diawali dengan merencanakan apa saja kebutuhan aplikasi yang akan dibuat seperti fiturfitur apa saja yang akan dibuat, siapa saja yang menjadi aktor atau pengguna aplikasi dan apa saja yang bisa dilakukan oleh aktor-aktor tersebut.

\section{Analysis}

Selanjutnya apa yang telah direncanakan pada tahap planning digambarkan ke dalam use case diagram. Use case diagram merupakan diagram yang bisa digunakan untuk menggambarkan relasi antara aktor dengan sistem dan hanya menggambarkannya secara global [11]. Sedangkan menurut sumber lain, use case diagram bersifat statis dan memperlihatkan hubungan antara use case dengan aktor-aktor [13]. Aktor dari website OKOS adalah pencari kos, penyewa kos, pemilik kos dan admin. Dari use case itulah dapat diketahui apa saja yang dapat dilakukan pengguna di dalam website OKOS.

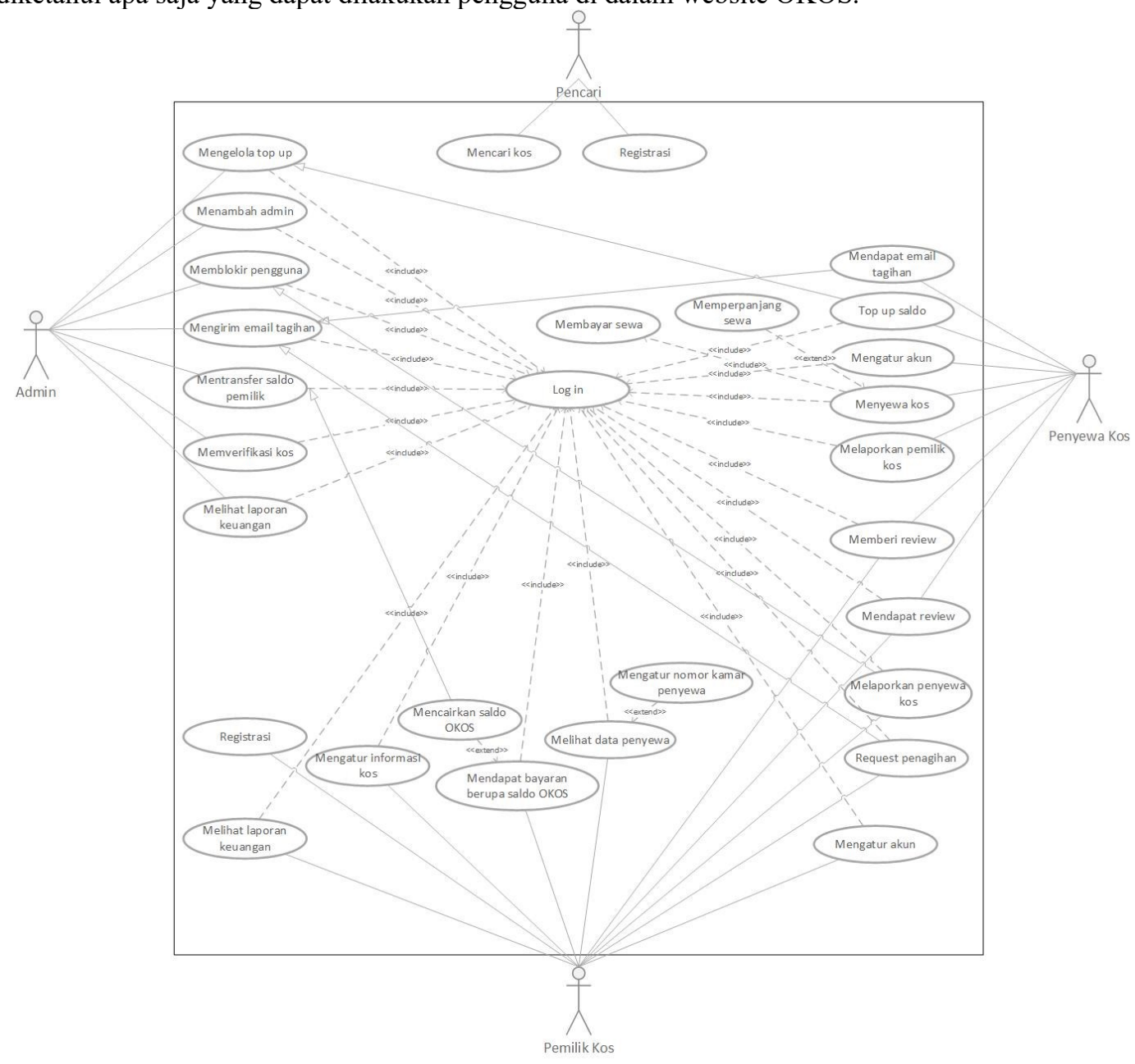

Gambar 1. Use Case Diagram OKOS

Website sistem informasi OKOS terdiri dari empat aktor yaitu pencari kos penyewa kos, pemilik kos, dan admin. Pencari kos tidak dapat melakukan pemesanan bila belum melakukan registrasi, jika pencari kos telah melakukan registrasi maka pencari kos menjadi penyewa kos dan bisa melakukan pemesanan kamar kos. Setelah penyewa melakukan pemesanan maka data kos akan diberikan kepada pemilik kos dan pemilik kos dapat mengatur nomor kamar penyewa. Data kos yang dimasukkan pemilik kos harus melalui persetujuan admin untuk memastikan data tersebut valid.

Setelah merancang use case diagram maka selanjutnya adalah merancang ERD. ERD merupakan diagram atau gambar yang menunjukkan suatu informasi disimpan, digunakan, dan dibuat pada sistem 
bisnis [14]. Sedangkan menurut sumber lain, ERD adalah diagram yang menunjukkan bagaimana entitas data utama saling terhubung [15].

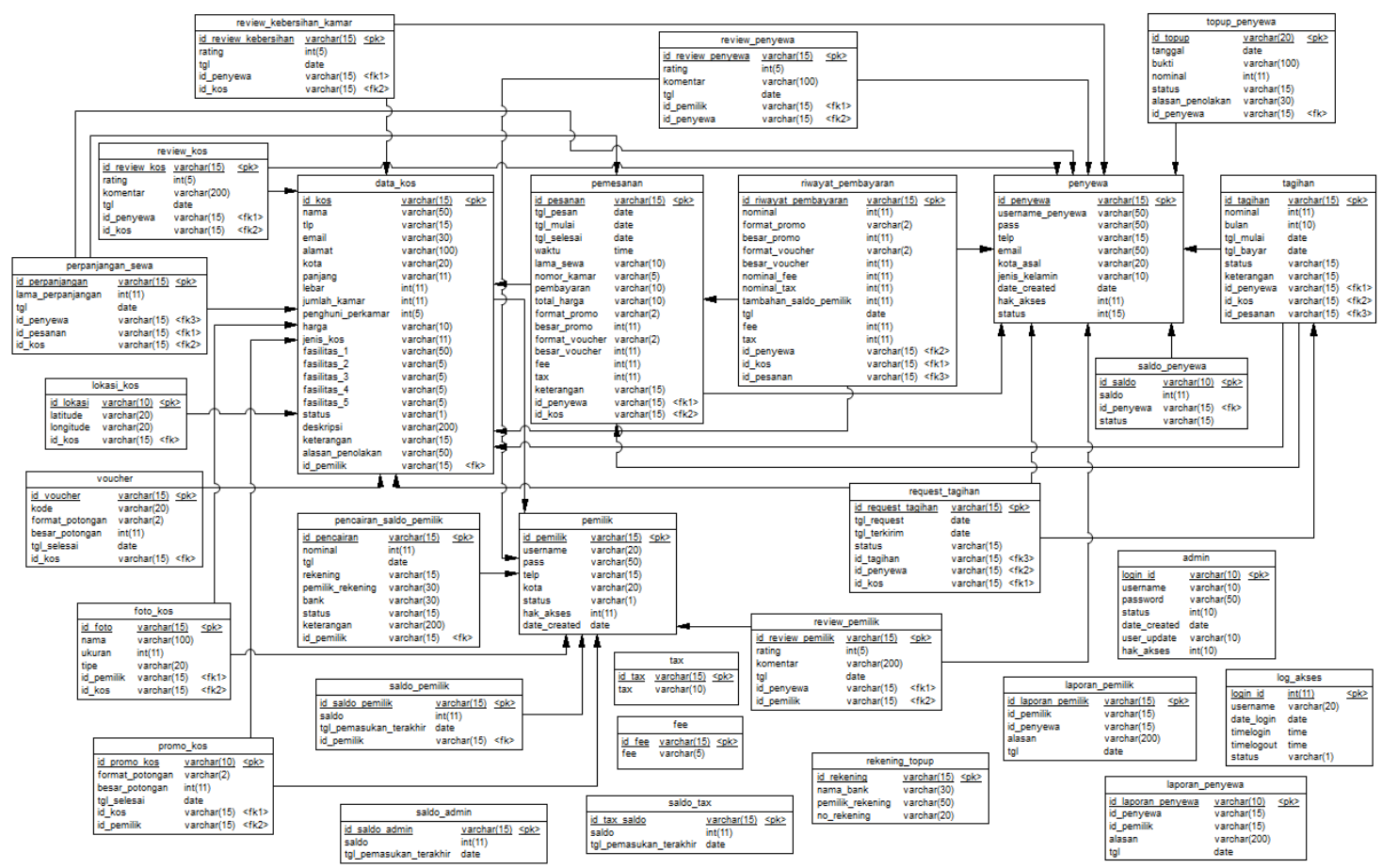

Gambar 2. Desain ERD OKOS

Pada database website OKOS terdiri dari 27 tabel. Tabel lokasi kos digunakan untuk menyimpan data koordinat kos yang ditambahkan oleh admin berdasarkan alamat kos yang didaftarkan oleh pemilik kos. Pada tabel data kos terdapat kolom dengan nama fasilitas_1 sampai dengan fasilitas 5 yang digunakan untuk menyimpan data fasilitas apa saja yang tersedia pada tempat kos. Tabel tagihan digunakan untuk menyimpan data tagihan yang dimiliki oleh penyewa. Tabel log akses digunakan untuk merekam aktivitas keluar dan masuknya pengguna OKOS. Tabel riwayat pembayaran berisi rekaman pembayaran yang telah dilakukan oleh penyewa dan data tersebut digunakan untuk menampilkan laporan keuangan pemilik kos maupun admin. Tabel laporan penyewa adalah tabel yang berfungsi untuk menyimpan laporan dari penyewa terhadap pemilik kos maupun kos yang disewa. Tabel laporan pemilik adalah tabel yang berfungsi untuk menyimpan laporan dari pemilik kos terhadap penyewa kos. Tabel saldo tax adalah tabel yang berfungsi untuk menyimpan pajak yang telah diambil dari setiap pembayaran penyewaan kos. Tabel saldo admin adalah tabel yang digunakan untuk menyimpan data keuntungan yang diperoleh dari seluruh pembayaran penyewaan kos.

\section{Design}

Langkah berikutnya setelah use case dan ERD dibuat maka selanjutnya dilakukan pembuatan desain tampilan dari website OKOS. Pembuatan desain tampilan dilakukan untuk melihat kekurangan yang ada pada use case dan ERD yang telah dibuat, selain itu agar pada tahap pengerjaan website jadi lebih terstruktur. 


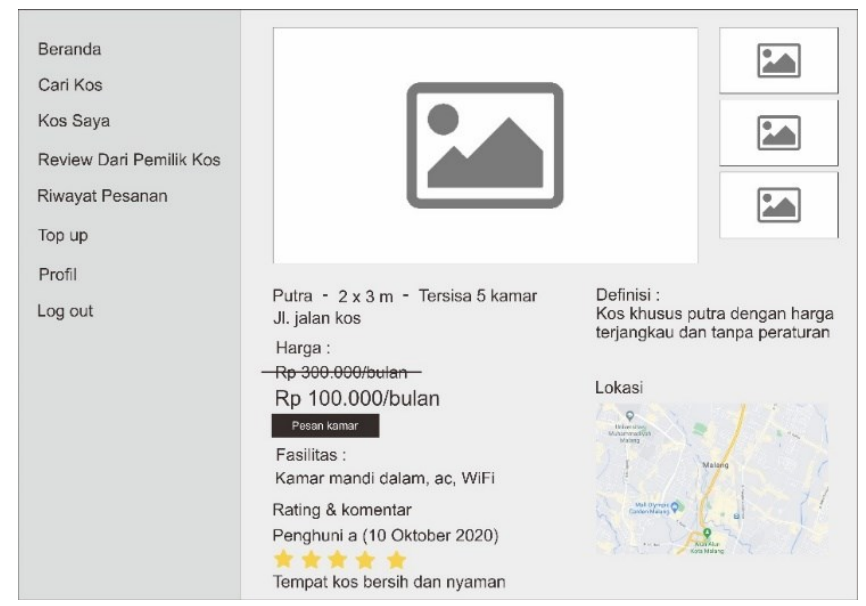

Gambar 3. Rancangan Halaman Detail Kos

Pada rancangan halaman detail kos, pencari dapat melihat informasi dari kos yang ingin di lihat secara detail. Pencari akan mendapatkan informasi tentang foto kos, jenis kos, luas kamar, kamar yang tersisa, alamat, harga asli, harga diskon, fasilitas, rating kos, dan deskripsi yang bisa saja berisi peraturan kos tersebut. untuk melakukan pemesanan pencari akan dialihkan ke halaman registrasi untuk mendaftarkan dirinya.

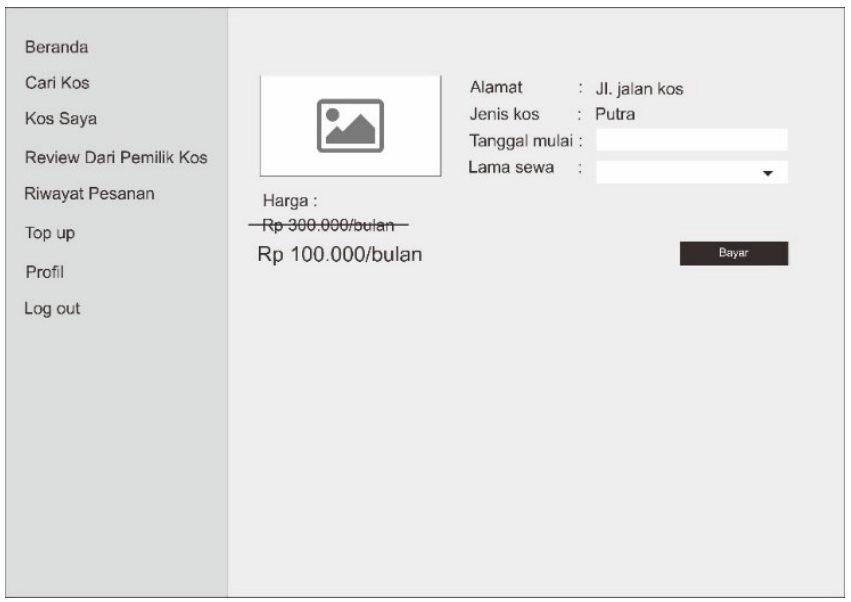

Gambar 4. Rancangan Pemesanan Kamar

Pada rancangan halaman pemesanan kamar, penyewa akan diminta untuk memasukkan tanggal mulai sewa kos dan durasi sewa yang terdiri dari 1 bulan, 3 bulan, 6 bulan, dan 12 bulan.

\section{Implementation}

Setelah desain tampilan selesai dibuat maka tahap selanjutnya adalah tahap pembuatan website OKOS. Tahap awal dari pembuatan website adalah membuat tampilan statis berdasarkan rancangan tampilan yang telah dibuat. Tampilan dari website OKOS dapat menyesuaikan dengan ukuran layar yang digunakan untuk website tersebut, sehingga ketika pengguna membuka website OKOS di smartphone tampilan yang muncul masih tertata rapi dan tidak berantakan. Selanjutnya setelah tampilan selesai dibuat maka dilakukan pembuatan database sesuai dengan rancangan ERD. Setelah tampilan dan database dibuat maka tahap yang terakhir adalah menjadikan website yang sebelumnya statis menjadi dinamis agar dapat digunakan sesuai dengan rancangan use case. 
Testing

Setelah website dibuat maka dilakukan testing pada website. Testing dilakukan untuk memastikan bahwa website yang dikerjakan berjalan dengan baik dan sesuai dengan apa yang telah direncanakan.

\section{Maintenance}

Dalam tahap maintenance, kesalahan-kesalahan yang ditemukan pada saat melakukan testing di analisa penyebabnya kemudian diperbaiki agar sistem dapat bekerja dengan sebagaimana mestinya.

\section{Hasil dan Pembahasan}

\section{Pencari Kos}

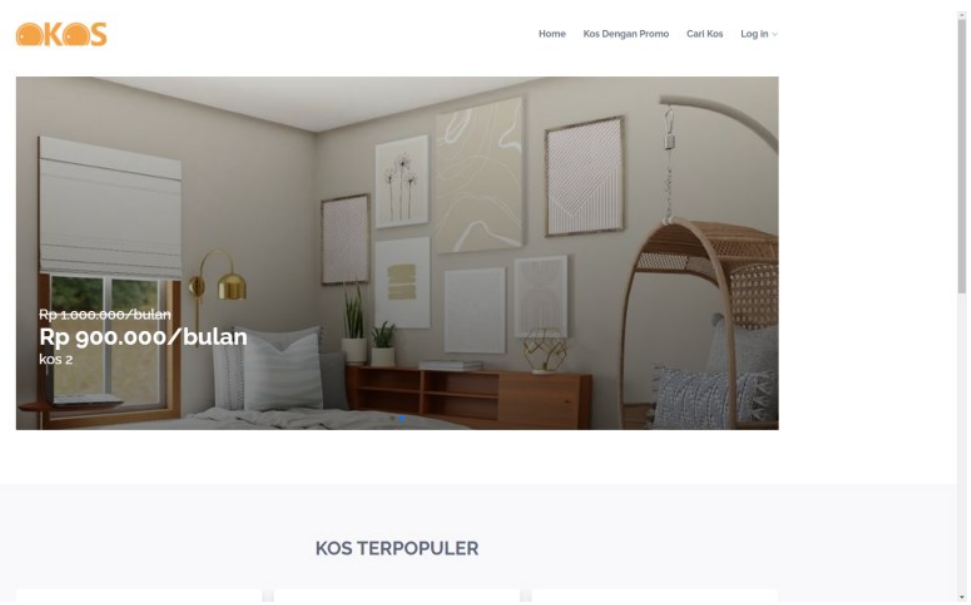

Gambar 5. Halaman Utama Pencari Kos

Pada halaman utama, pencari akan dapat melihat kos yang sedang mengadakan promo, kos terpopuler, dan pencarian kos. Kos terpopuler ditampilkan berdasarkan kos-kos yang paling banyak disewa oleh penyewa kos.

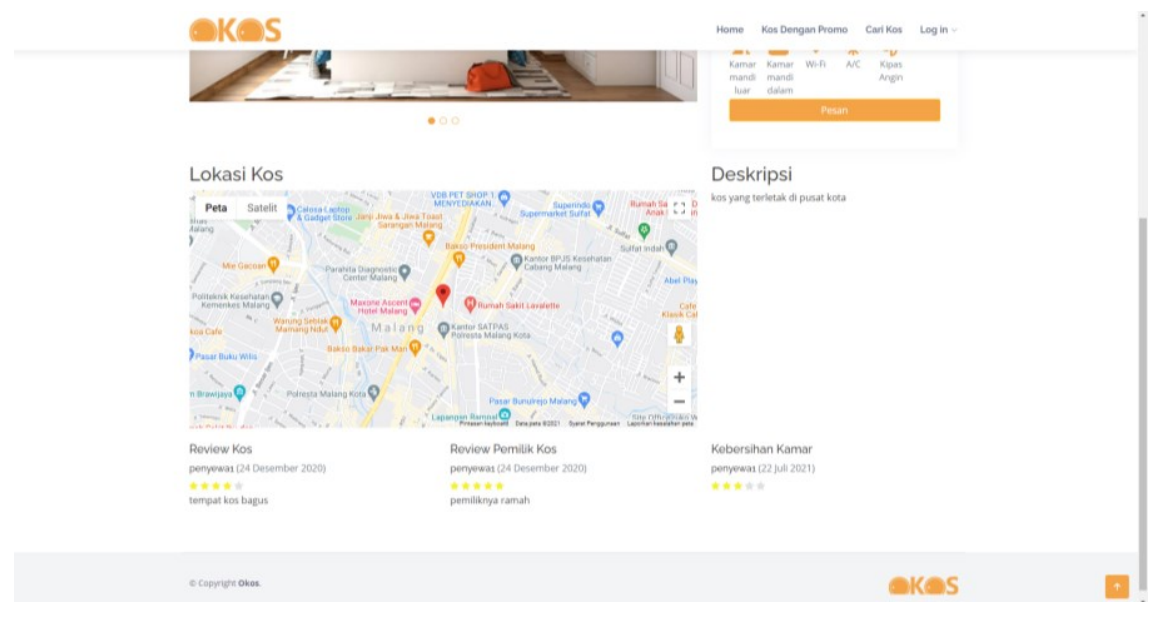

Gambar 6. Halaman Detail Kos Pencari

Pada halaman detail kos, sistem akan menampilkan berbagai informasi tentang kos seperti gambar, alamat, jenis kos, luas kamar, sisa kamar, harga, fasilitas, peta lokasi kos, deskripsi, review kos, dan review pemilik kos. Jika pencari kos menekan tombol "pesan" maka sistem akan mengarahkan ke halaman log in karena untuk melakukan penyewaan kamar kos harus melakukan log in terlebih dahulu. 


\section{Penyewa Kos}

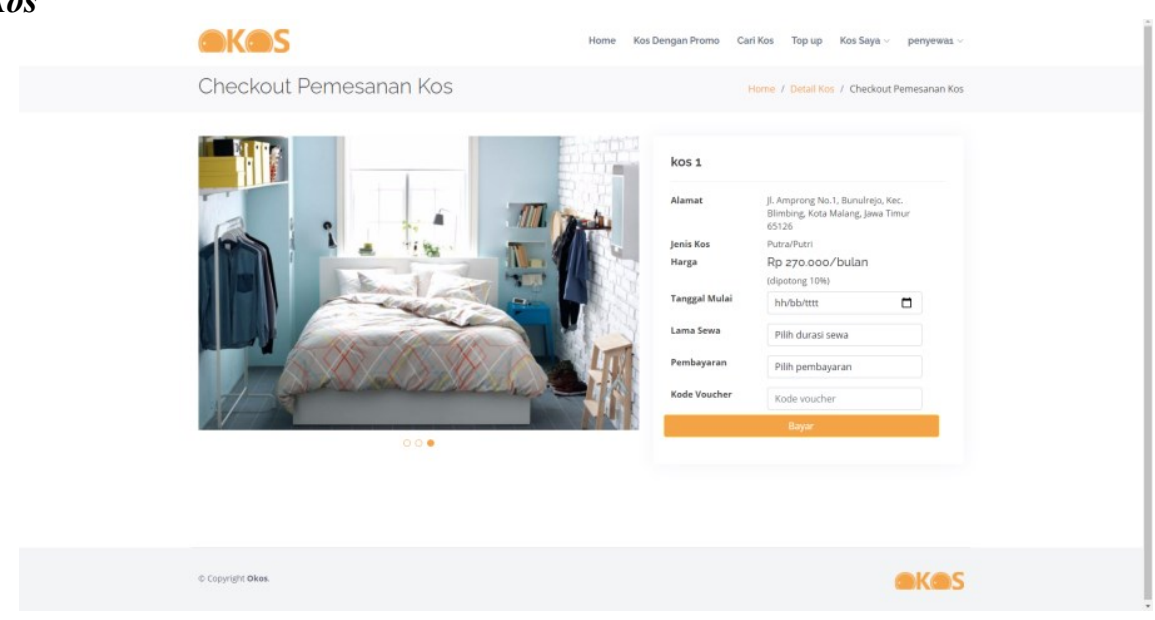

Gambar 7. Checkout Pemesanan Kos

Pada halaman checkout pemesanan kos, penyewa akan diminta untuk memasukkan tanggal mulai sewa kos, lama sewa, pilihan pembayaran yang terdiri dari pilihan bayar per bulan atau bayar di muka, dan kode voucher yang bersifat opsional.

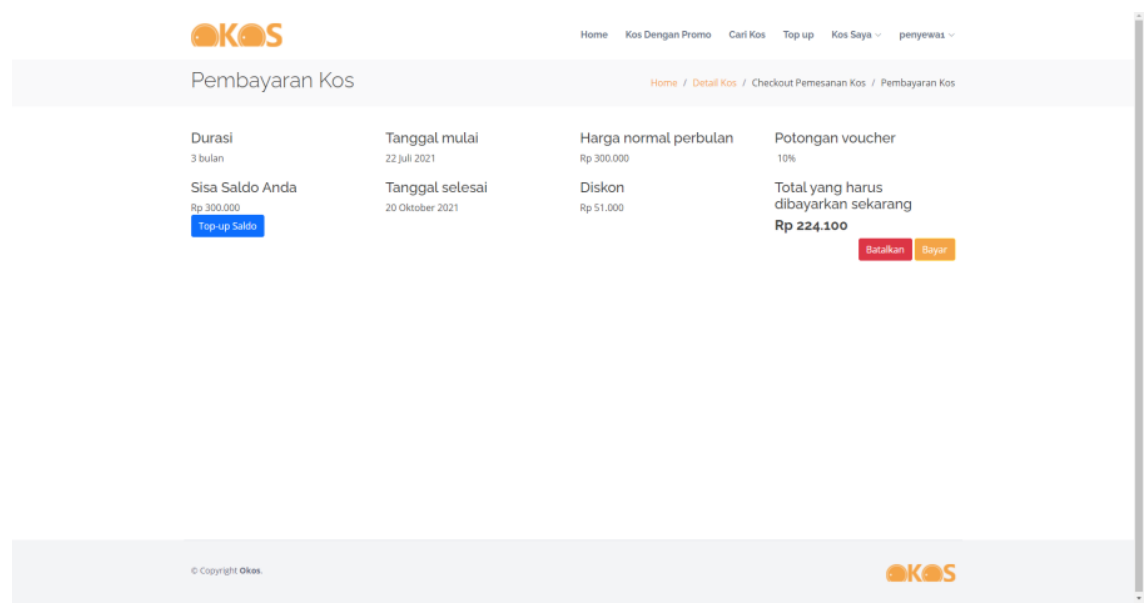

Gambar 8. Pembayaran Sewa Kos

Setelah melakukan checkout, penyewa akan dialihkan ke halaman pembayaran kos yang berisi informasi penyewaan kos seperti durasi sewa, tanggal mulai, harga normal, potongan voucher, sisa saldo penyewa, tanggal selesai, diskon, dan total yang harus dibayarkan saat ini. Jika di halaman checkout penyewa memilih pembayaran per bulan maka yang harus dibayarkan adalah biaya sewa pada bulan pertama, sedangkan jika di halaman checkout penyewa memilih pembayaran di muka maka yang harus dibayarkan adalah total biaya dari seluruh durasi lama sewa. 


\section{Pemilik Kos}

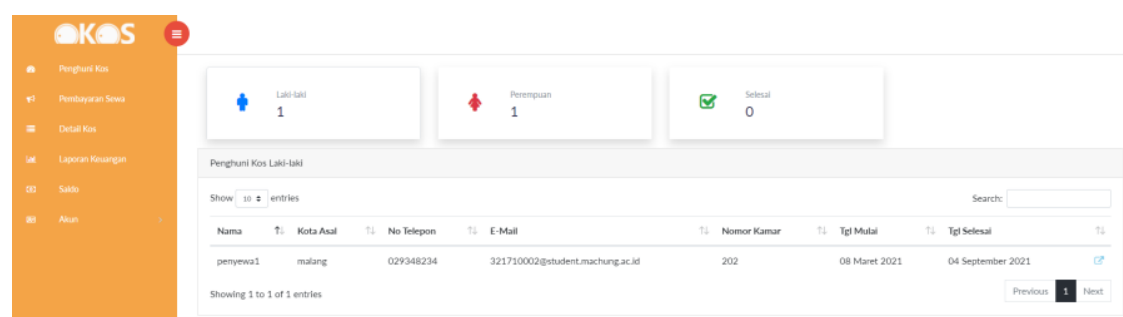

Gambar 9. Halaman Utama Pemilik Kos

Di halaman utama, pemilik kos akan diberikan informasi tentang data penyewa kos dari yang saat ini sedang menyewa kos sampai dengan yang masa sewanya sudah selesai.

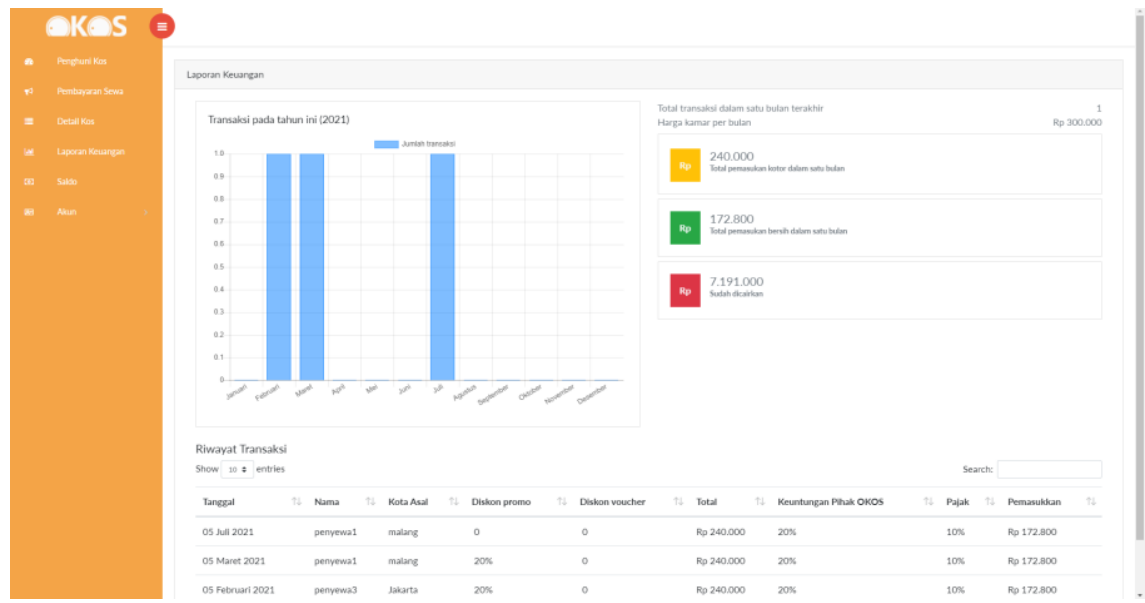

Gambar 10. Laporan Keuangan Pemilik Kos

Pada halaman laporan keuangan, pemilik kos dapat melihat detail informasi dari pembayaran yang dilakukan oleh penyewa termasuk pemasukan yang diterima setelah dikurangi pajak dan keuntungan pihak OKOS. Pemilik kos juga dapat melihat grafik transaksi yang terjadi dalam satu tahun. Berikut ini adalah rumus dari penghitungan keuntungan pemilik kos, keuntungan pihak OKOS, dan pajak.

Keuntungan pihak OKOS $=$ harga sewa $\times$ persentase keuntungan OKOS

Pajak $=($ harga sewa - Keuntungan pihak OKOS $) \times$ persentase pajak

Keuntungan pemilik kos = harga sewa - Keuntungan pihak OKOS - Pajak 
Admin

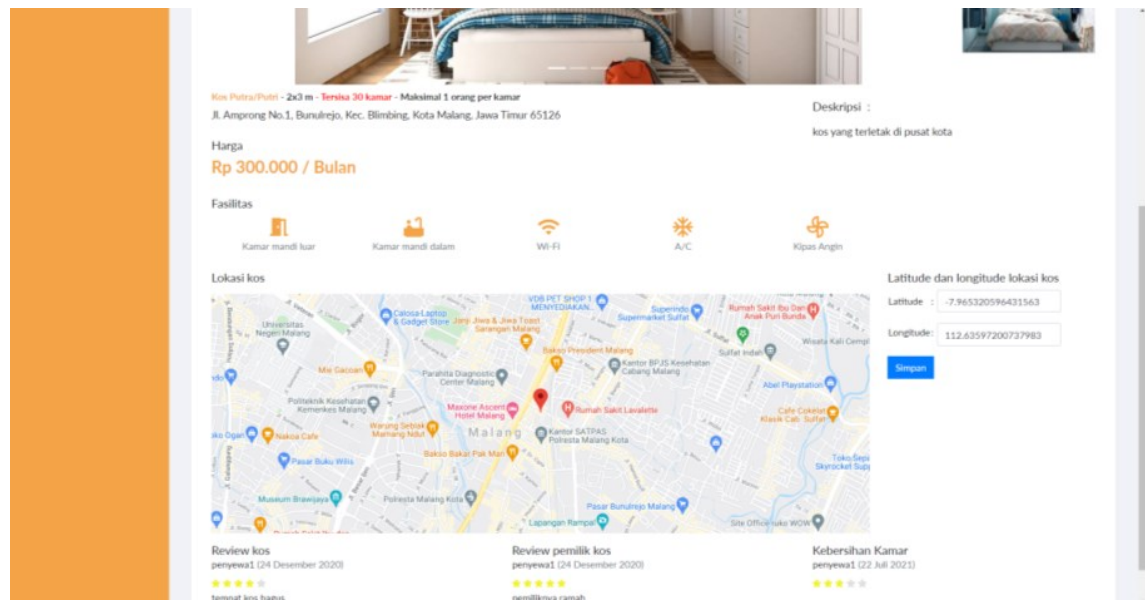

Gambar 11. Halaman Detail Kos Setelah Dikonfirmasi

Pada halaman detail kos yang telah dikonfirmasi, admin dapat melihat informasi kos termasuk peta lokasi dan juga review. Admin juga dapat mengubah koordinat yang sebelumnya telah ditambahkan.

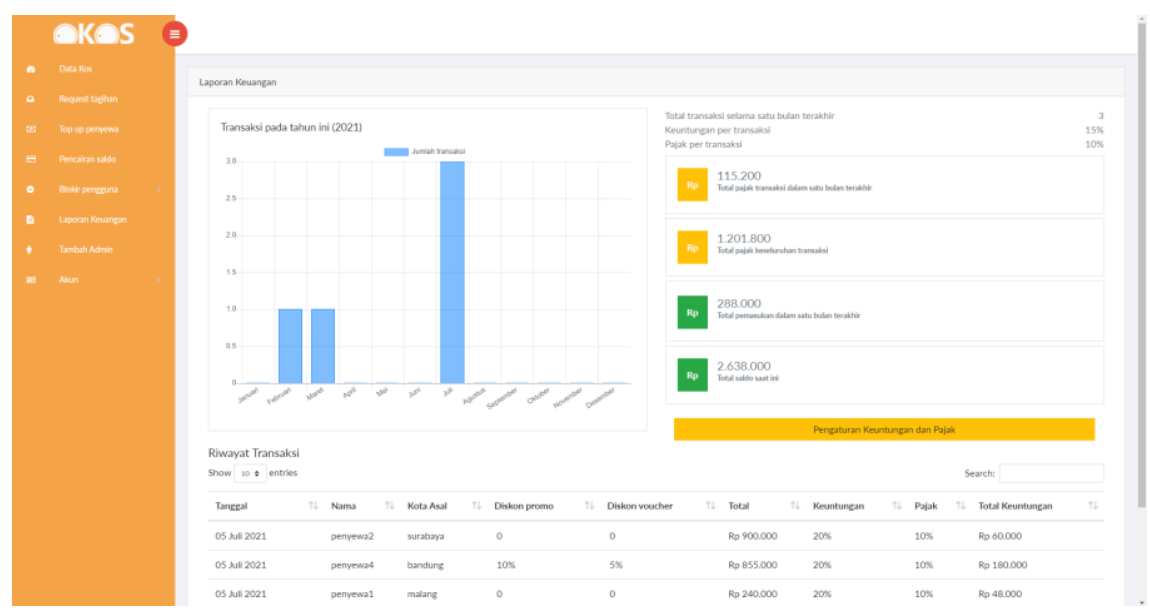

Gambar 12. Laporan Keuangan Admin

Pada halaman laporan keuangan admin, admin dapat melihat grafik transaksi tahun ini, total pajak, total pemasukan, dan riwayat transaksi. Admin juga dapat mengatur besaran persentase keuntungan dan pajak yang secara otomatis dikalkulasi oleh sistem saat penyewa kos melakukan pembayaran. Rumus untuk penghitungan keuntungan pemilik kos, keuntungan pihak OKOS, dan pajak sama seperti pada laporan keuangan pemilik kos.

\section{Kesimpulan}

Dari dilakukannya pembuatan website sistem informasi OKOS maka dapat diambil kesimpulan bahwa OKOS dapat mempermudah pemilik kos dan pencari kos karena OKOS dapat menjadi perantara antara pencari kos dengan pemilik kos walau ada di kota yang berbeda karena kapan pun dan di mana pun pencari kos dapat mencari kos yang sesuai dengan keinginan. Selain itu OKOS menyediakan informasi yang cukup lengkap sehingga pencari kos dapat memilih kos berdasarkan jenis kos, fasilitas, harga, luas kamar, penghuni maksimal per kamar, hingga peta lokasi kos.

Kos yang disewakan oleh pemilik kos dapat lebih diminati oleh pencari kos karena OKOS menyediakan fitur promo dan voucher yang besaran potongan harga dan batas waktunya dapat ditentukan oleh pemilik kos. Selain itu dengan adanya fitur peta Google Maps, pencari kos akan dapat melihat apa saja 
yang ada di sekitar kos, sehingga jika tempat kos berada di lokasi yang strategis maka akan menarik minat pencari kos lebih banyak.

\section{Daftar Pustaka}

[1] R. W. Permana, "Malang Sebagai Kota Pendidikan Sejak Masa Hindia Belanda," Merdeka.com, 2016.

[2] H. Y. Prabowo, "Selain Penambahan Pendatang, Mahasiswa Juga Punya Sumbangan Lain ke Kota Malang, Yaitu ...," www.suryamalang.tribunnews.com, 2017.

[3] D. Novianty and T. Rahmat, "Lima Aplikasi Peta Digital Pemandu Mudik," suara.com, 2019. .

[4] Suzuki, "5 Aplikasi GPS Terbaik Menemani Perjalanan Kamu | Suzuki Indonesia.".

[5] H. Wadi, Pemrograman Android Untuk Aplikasi Google Maps. 2019.

[6] M. Y. H. Setyawan and A. S. Munari, Panduan Lengkap Membangun Sistem Monitoring Kinerja Mahasiswa Internship. 2020.

[7] Mukhlis, Danuri, and B. Syahputra, "Aplikasi Android Peta Sekolah Bengkalis Menggunakan Google Map API," INOVTEK polbeng, vol. 2, no. 1, pp. 48-56, 2017.

[8] A. Rahmenda, M. Awaludding, and A. L. Nugraha, "PEMBUATAN APLIKASI SEBARAN LOKASI KOS BERBASIS WEBGIS MENGGUNAKAN GOOGLE MAP API (Studi Kasus: Area Kampus Universitas Diponegoro)," J. Geod. UNDIP, vol. 6, no. 1, pp. 12-20, 2017.

[9] A. G. Pradini, "SISTEM INFORMASI PEMESANAN RUMAH KOST DI WILAYAH PURWOKERTO UTARA BERBASIS WEB," BSI, 2019.

[10] A. Sagita and B. K. Simpony, "Web Sistem Informasi Pencarian Info Kostan Menggunakan Google Maps API 3," IJCIT(Indonesian J. Comput. Inf. Technol., vol. 3, no. 1, pp. 18-25, 2018.

[11] S. Mulyani, Analisis dan Perancangan Sistem Informasi Manajemen Keuangan Daerah: Notasi Pemodelan. Abdi Sistematika, 2017.

[12] A. H. Fansury, M. A. Rahman, and B. Jabu, Developing Mobile English Application As Teaching Media. Deepublish, 2021.

[13] M. Muslihidin and Oktafianto, Analisis dan Perancangan Sistem Informasi Menggunakan Model Terstruktur dan UML. Penerbit Andi, 2016.

[14] H. Al Fatta, Analisis dan Perancangan Sistem Informasi untuk Keunggulan Bersaing Perusahaan dan Organisasi Modern. Penerbit Andi, 2017.

[15] D. C. Yen, The Information System Consultant's Handbook. CRC Press, 2019. 